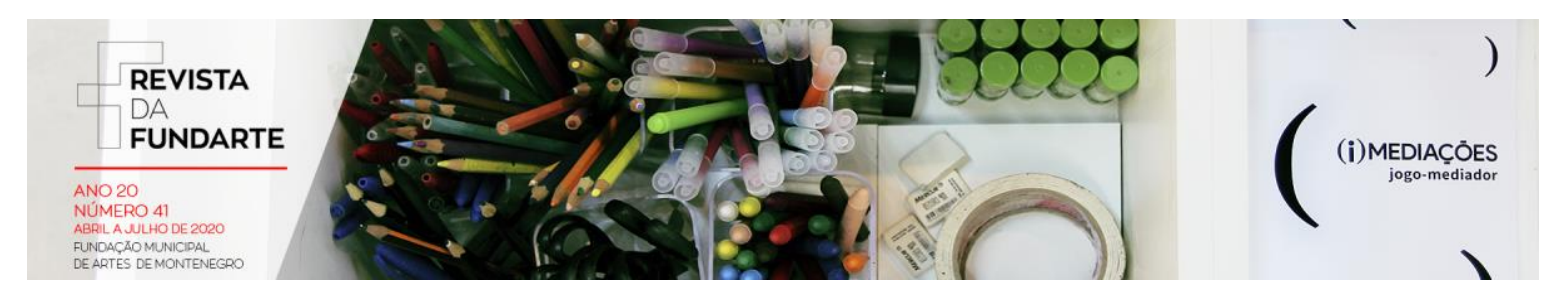

\title{
JOGO, BRINCADEIRA, PRESENÇA: CORPOS LÚDICOS E EXPRESSIVOS EM AULAS DE DANÇA NA ESCOLA
}

Joice Soares Rodrigues

Helena Thofehrn Lessa

DOI: http://dx.doi.org/10.19179/2F2319-0868.731

RODRIGUES, Joice Soares; LESSA, Helena Thofehrn. Jogo, brincadeira, presença: corpos lúdicos e expressivos em aulas de dança na escola. Revista da FUNDARTE. Montenegro, p.01-18, ano 20, no 41, Abril/Junho de 2020.

Disponível em: http://.seer.fundarte.rs.gov.br/index.php/RevistadaFundarte/index> 30 de junho de 2020. 


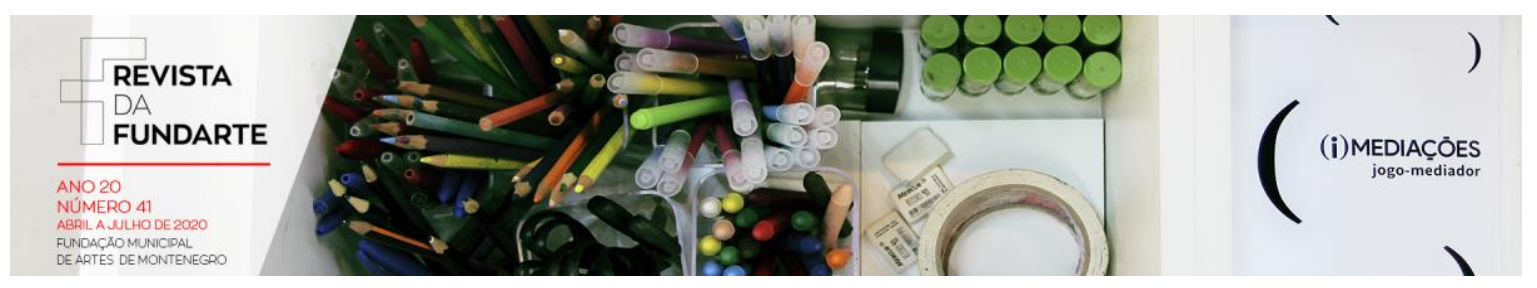

\title{
JOGO, BRINCADEIRA, PRESENÇA: CORPOS LÚDICOS E EXPRESSIVOS EM AULAS DE DANÇA NA ESCOLA
}

Joice Soares Rodrigues ${ }^{1}$

Helena Thofehrn Lessa

\begin{abstract}
Resumo: Este trabalho tem como objetivo discutir o uso do lúdico em aulas de Dança na escola a partir de uma pesquisa realizada com duas professoras que atuam na disciplina de Artes na rede pública de Pelotas. Os diálogos e as reflexões são feitos com base nos relatos das professoras e no cruzamento com fontes teóricas, trazendo discussões sobre noções de ludicidade e aspectos que a caracterizam. Percebe-se que o uso do lúdico nas aulas de Dança tem suas dificuldades, facilidades e versatilidades, mas que a entrega sincera na experiência proposta parece ser o elemento mais crucial nesse tipo de abordagem.
\end{abstract}

Palavras-chave: Educação; Docência; Ludicidade.

\section{GAME, PLAY, PRESENCE: PLAYFUL AND EXPRESSIVE BODIES IN DANCE CLASSES AT SCHOOL}

\begin{abstract}
This paper aims to discuss the use of the ludic in dance classes at school, from a research conducted with two teachers who work in the Arts discipline in the public network of the city of Pelotas. The dialogues and the reflections are based on the teachers' reports and the intersection with theoretical sources, bringing reflections on notions of playfulness and aspects that characterize it. The use of playfulness in Dance classes has its difficulties, facilities and versatility, but that the sincere presence in the proposed experience seems to be the most crucial element in this type of approach.

Keywords: Education; Teaching; Playfulness.
\end{abstract}

\section{Introdução}

Este trabalho tem como tema o uso do lúdico nas aulas de Dança e configurase como um estudo de caso com duas professoras licenciadas em Dança que atuam na disciplina de Artes na rede pública de Pelotas. A pesquisa é oriunda do trabalho

\footnotetext{
1 Graduada em Dança - Licenciatura pela Universidade Federal de Pelotas. Atuou como bolsista do Programa Interdisciplinar de Incentivo à Docência (PIBID) por três anos e durante esse período elaborou diversos projetos e oficinas voltados a alunos dos anos iniciais do ensino fundamental de escolas públicas.

2 Professora de dança e Fisioterapeuta. Mestra e Doutora em Educação Física pela Universidade Federal de Pelotas na área de concentração Movimento humano, educação e sociedade - Linha de pesquisa Comportamento Motor. Foi Professora Substituta do Curso de Dança - Licenciatura da Universidade Federal de Pelotas. Atualmente é membro do Grupo de Pesquisa OMEGA Observatório de Memória, Educação, Gênero e Arte.
}

RODRIGUES, Joice Soares; LESSA, Helena Thofehrn. Jogo, brincadeira, presença: corpos lúdicos e expressivos em aulas de dança na escola. Revista da FUNDARTE. Montenegro, p.01-18, ano 20, oㅡ 41, Abril/Junho de 2020.

Disponível em: http://.seer.fundarte.rs.gov.br/index.php/RevistadaFundarte/index> 30 de junho de 2020. 


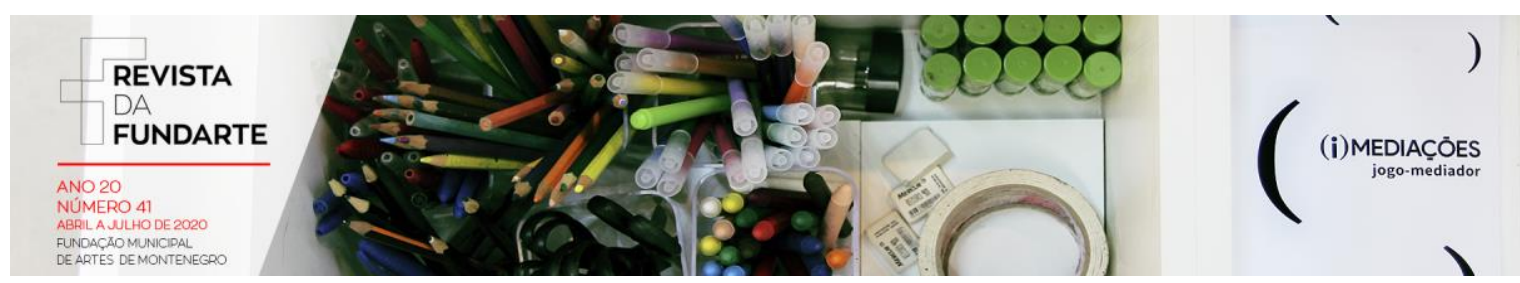

de conclusão de curso ${ }^{3}$ da autora principal e foi motivado pela percepção de um forte interesse e vínculo com a ludicidade durante as suas experiências docentes ${ }^{4}$. Essas incluíam especialmente jogos e brincadeiras corporais em que a sua presença se desprendia do papel de guiadora e alcançava um estado lúdico com os alunos ao participar ativamente das atividades, deixando-os mais motivados e interessados a mergulharem nas atividades.

A busca para entender como é feito o uso do lúdico nas aulas das professoras licenciadas em Dança também foi motivada pela possibilidade de enriquecer a formação de professores (as) e pesquisadores(as) da área da Dança, carregando a expectativa de trazer um olhar ampliado e sensível acerca do papel da ludicidade nas aulas. Com esse interesse, questiona-se se as licenciadas em Dança que atuam nas escolas públicas de Pelotas também utilizam a ludicidade em suas aulas. Se sim, de que forma ela é abordada? A partir dessas questões norteadoras, buscou-se, de forma mais específica, discutir possibilidades de relação entre ludicidade e dança na escola; identificar o uso do lúdico no ensino de Dança nas escolas públicas na cidade de Pelotas; entender, comparar e problematizar o modo como cada professora de Dança utiliza a ludicidade em suas aulas nas escolas públicas de Pelotas.

Foram realizadas entrevistas semi-estruturadas em maio e julho de 2018 , as quais foram gravadas com o consentimento e autorização das duas professoras. As perguntas da entrevista foram elaboradas levando em consideração os objetivos da

\footnotetext{
3 Trabalho de conclusão de curso intitulado "O lúdico e a dança: olhares das licenciadas em Dança que atuam em escolas da rede pública de Pelotas/RS", defendido e aprovado em dezembro de 2018 no curso de Dança - Licenciatura da Universidade Federal de Pelotas.

${ }^{4}$ Durante o período em que foi aluna do curso de Dança - Licenciatura da Universidade Federal de Pelotas, a autora teve diferentes experiências docentes por meio dos estágios curriculares e projetos de ensino. Atuou como bolsista do Programa Interdisciplinar de Incentivo à Docência (PIBID) por três anos e durante esse período elaborou diversos projetos e oficinas voltados a alunos dos anos iniciais do ensino fundamental de escolas públicas de Pelotas.
}

RODRIGUES, Joice Soares; LESSA, Helena Thofehrn. Jogo, brincadeira, presença: corpos lúdicos e expressivos em aulas de dança na escola. Revista da FUNDARTE. Montenegro, p.01-18, ano 20, oㅡ 41, Abril/Junho de 2020.

Disponível em: http://.seer.fundarte.rs.gov.br/index.php/RevistadaFundarte/index> 30 de junho de 2020. 


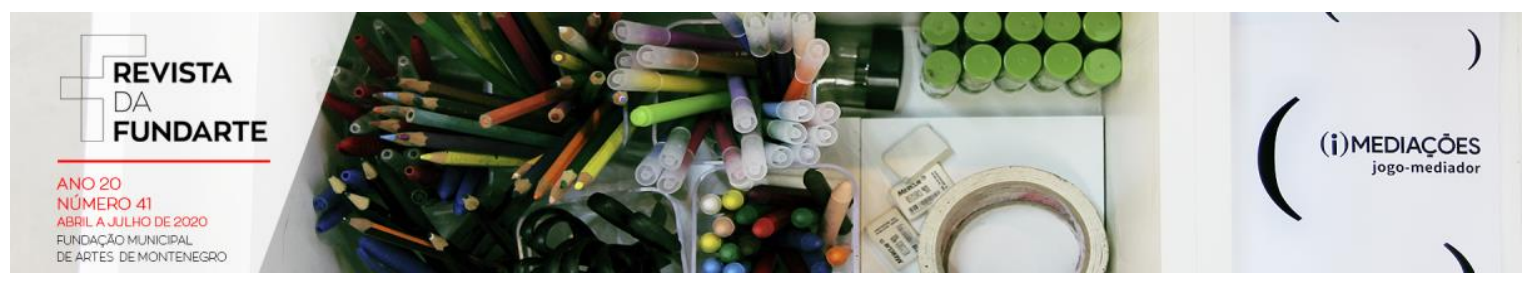

pesquisa e organizadas de acordo com um roteiro flexível que se desenrolava a partir das respostas fornecidas por cada professora. Por fim, foi feita uma análise comparativa, em que destacaram-se as principais diferenças e semelhanças sobre o uso do lúdico nas aulas das entrevistadas ${ }^{5}$.

\section{A professora 6 lúdica na escola}

A definição filosófica e histórica da palavra lúdico vem da derivação do latim "ludus", que significa "jogos" e "brincar". Segundo Huizinga (2000), o jogo é uma criação cultural histórica que tem suas bases biológicas, ou seja, antigamente o jogo era um tipo de necessidade de preservação da espécie, servindo para busca de alimentos e defesa contra animais maiores. Para o autor, foi por meio do lúdico que o ser humano conseguiu iniciar o seu desenvolvimento de comunicação e se apropriou de conhecimentos sobre o mundo em que vivia, tendo, assim, recursos para a criação de ferramentas para a sobrevivência. Atualmente, o jogo é determinado pelo autor como uma ação voluntária, tendo uma atenção maior direcionada ao processo de brincar em si do que aos possíveis resultados alcançados.

O lúdico também é entendido como uma experiência interna, em que "os estudos de Luckesi $(2002,2004)$ tem uma importante contribuição, pois possibilitam a compreensão da ludicidade como um caráter interno de absorção na realização da atividade [...]" (CANDA, 2006, p.178). Tendo como base os apontamentos de

\footnotetext{
${ }^{5}$ A professora Jaciara ministra aulas para a Educação de Jovens e Adultos (EJA), que engloba do 6은 ano do ensino fundamental até o ensino médio, na Escola Estadual Fernando Treptow. A professora Tauana atua nos anos finais do ensino fundamental ( $5^{\circ}$ ao $9^{\circ}$ ano) na Escola Municipal Osvaldo Cruz. Ambas as professoras são egressas do curso de Dança - Licenciatura da Universidade Federal de Pelotas.

6 Optamos por utilizar o termo "professora" (na flexão de gênero feminino) no título e no decorrer do trabalho porque as integrantes da pesquisa são na sua totalidade mulheres: as pesquisadoras e as professoras entrevistadas.
}

RODRIGUES, Joice Soares; LESSA, Helena Thofehrn. Jogo, brincadeira, presença: corpos lúdicos e expressivos em aulas de dança na escola. Revista da FUNDARTE. Montenegro, p.01-18, ano 20, no 41, Abril/Junho de 2020.

Disponível em: http://.seer.fundarte.rs.gov.br/index.php/RevistadaFundarte/index> 30 de junho de 2020. 


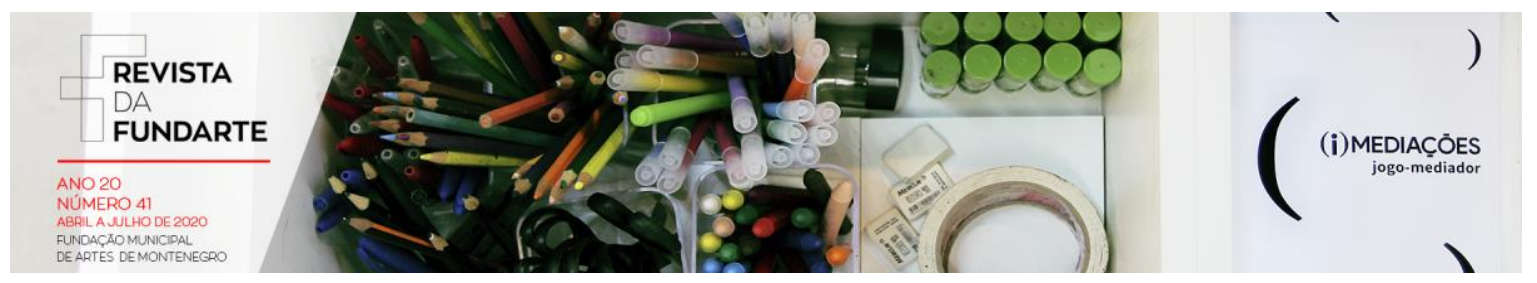

Luckesi, Canda (2006) propõe que a atividade lúdica pode proporcionar uma experiência individual para cada sujeito, como, por exemplo, trazer à tona a lembrança de um evento ou a recordação de uma situação do passado.

Almeida (2018) também cita Luckesi em seu texto, afirmando que uma atividade lúdica vai além da experiência de diversão normalmente atribuída ao seu caráter durante o desenvolvimento de um jogo ou brincadeira:

A respeito do lúdico, Luckesi (2005) afirma que uma atividade lúdica é aquela que propicia a plenitude da experiência, buscando uma entrega total: mental, emocional e física; é um momento de imersão, de mergulho na vivência que vai além do sentido mais simplista do senso comum sobre o riso e a diversão. (ALMEIDA, 2018, p.18).

Trabalhar com a ludicidade pode, de fato, ser uma experiência feliz e divertida, mas significa também ir além desse significado. Por meio do lúdico cada sujeito é tocado de uma forma diferente e, por isso, de forma imprevisível: vai depender de como cada aluno (a) vai responder internamente e externamente. Canda (2006, p.169) sugere que

[...] é necessário salientar que uma mesma brincadeira ou um jogo pode não ser lúdico para um participante e lúdico para outro, pois o grau de envolvimento e de significação do brincar quem constrói é o próprio sujeito. Desse modo, o sujeito pode participar de um jogo, mas não envolver-se com ele, mesmo quando estiver mobilizando o seu corpo; neste caso, a atividade não tem uma representação lúdica para ele, pois a participação foi apenas externa.

A ludicidade pode, então, ser interpretada de diferentes modos, pois cada sujeito tem um grau de envolvimento e participação durante as atividades. Dotada de versatilidade, a ludicidade acaba se moldando às necessidades dos indivíduos brincantes, podendo ser explorada e utilizada de inúmeras formas. Mas, para que isso seja possível, a educadora precisa também ser dotada de flexibilidade para saber se beneficiar da grandeza deste universo. Segundo a autora Pereira:

RODRIGUES, Joice Soares; LESSA, Helena Thofehrn. Jogo, brincadeira, presença: corpos lúdicos e expressivos em aulas de dança na escola. Revista da FUNDARTE. Montenegro, p.01-18, ano 20, oㅡ 41, Abril/Junho de 2020.

Disponível em: http://.seer.fundarte.rs.gov.br/index.php/RevistadaFundarte/index> 30 de junho de 2020. 


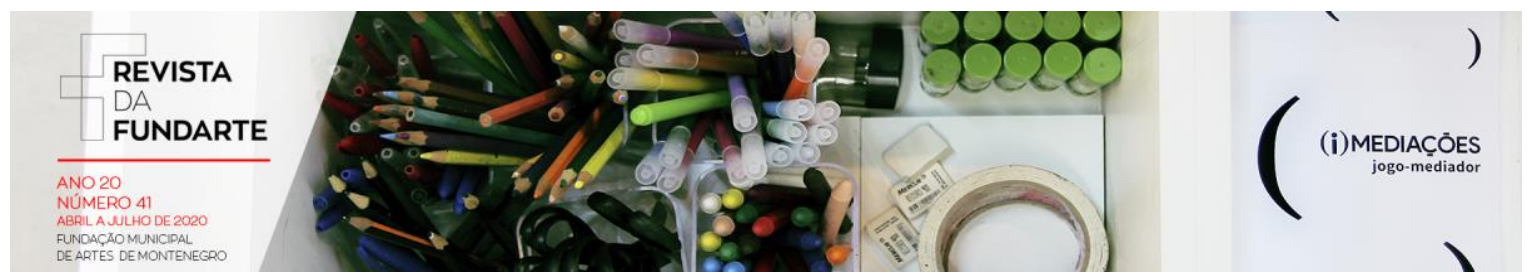

Muito mais que teorias, técnicas de ensino, metodologias ou uma parafernália lúdica (jogos, brinquedos, objetos...), a presença da ludicidade exige envolvimento afetivo do profissional, sua crença nas possibilidades da sua ação para que não se prenda a uma visão utilitária das atividades lúdicas. (PEREIRA, 2015, p.700).

Para se trabalhar com a ludicidade na escola, é necessário mais do que levar atividades e materiais: exige entrega ao trabalho que será desenvolvido. Não havendo envolvimento sincero da docente no que é proposto acaba por se tornar somente uma prática recreativa em sala de aula.

Para que o conceito de ludicidade seja melhor compreendido na prática, é importante considerar algumas características importantes sintetizadas pela autora Cilene Canda (2006) em um estudo sobre a obra de Ramos (2000). Seis características são apontadas: 1) liberdade de ação do jogador: sentir-se livre permite a abertura para as circunstâncias de determinada brincadeira, enquanto 0 caráter de imposição e obrigatoriedade do jogo torna-se contraditório com o sentido de ludicidade; 2) flexibilidade: capacidade de reestruturar a atividade que estiver desenvolvendo, ou seja, as regras podem ser modificadas mediante o acordo prévio com o grupo participante da atividade lúdica; 3) relevância do processo de brincar: não há uma preocupação com os produtos, resultados ou o alcance de objetivos previamente estabelecidos. O objetivo da atividade se encerra nela mesma, importando apenas o momento presente de plenitude; 4) incerteza dos resultados: 0 que importa é a ação do presente e o seu final deve ser sempre imprevisível; 5) controle interno: a ação de brincar é guiada pelo envolvimento na atividade e quem controla a ação são os sujeitos que participam da atividade e não a educadora; 6) intencionalidade daquele que brinca: todos os envolvidos devem estar com a intenção de brincar naquele momento. A atividade lúdica não deve ser imposta, mas trabalhada em forma de acordos coletivos.

Por meio das características elencadas, ficam evidentes os elementos que uma atividade lúdica deve ter para ocorrer de forma plena. Pensando nas aulas de

RODRIGUES, Joice Soares; LESSA, Helena Thofehrn. Jogo, brincadeira, presença: corpos lúdicos e expressivos em aulas de dança na escola. Revista da FUNDARTE. Montenegro, p.01-18, ano 20, no 41, Abril/Junho de 2020.

Disponível em: http://.seer.fundarte.rs.gov.br/index.php/RevistadaFundarte/index> 30 de junho de 2020. 


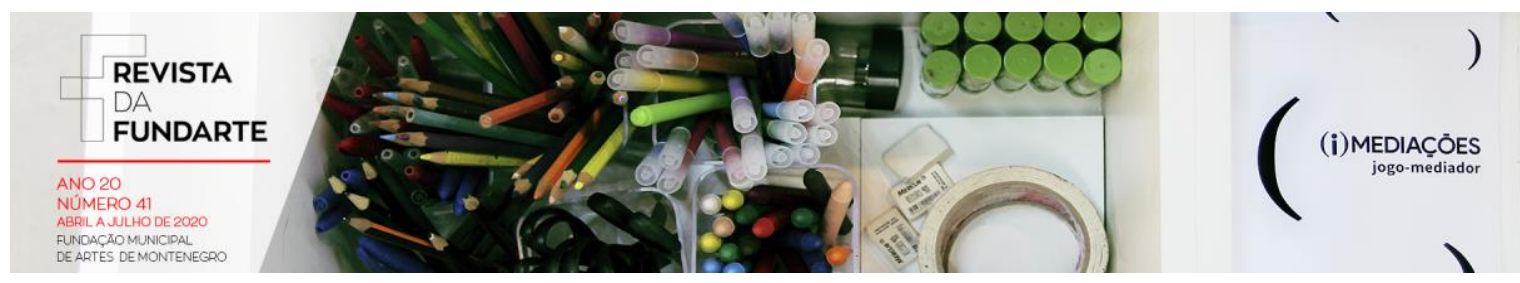

Dança, o uso da ludicidade pode contribuir para facilitar o entendimento dos conteúdos e pode ser vivenciado de inúmeras formas. No entanto, é importante ressaltar que a principal via de acesso utilizada para as atividades é o corpo, cabendo à professora de Dança oportunizar possibilidades do corpo protagonizar as atividades lúdicas.

\section{Corpos lúdicos e expressivos nas aulas de Dança: olhares de duas professoras}

O corpo propicia a percepção, o conhecimento e a interação com o mundo, permite ou limita o relacionamento com os objetos de brincar e jogar, as pessoas e os espaços com que brincamos e jogamos. Nesse sentido, cada corpo vai estabelecer e criar relações diferentes diante dos mesmos jogos e brincadeiras. De acordo com Isabel Marques (2008), o corpo não é somente um instrumento diante das brincadeiras, mas sim o protagonista de toda a cena lúdica.

O corpo é o brinquedo, o jogo e a brincadeira. O corpo que somos pode nos proporcionar situações e interações lúdicas sem necessariamente estarmos apoiados nas canetinhas coloridas, nos recortes, nas massinhas, nos jogos de encaixe, nas bexigas, nas bonecas e nos carrinhos (embora esses suportes sejam todos extremamente importantes, necessários e significativos para os corpos que brincam!). Corpos neles mesmos e por eles mesmos já brincam, jogam, inter-relacionam-se brincando e jogando. $O$ jogo e a brincadeira podem ser o próprio corpo. (MARQUES, 2008, p.156 157).

O corpo se torna lúdico quando está brincando e jogando consigo mesmo, com o meio físico que se encontra no momento e com os outros. Marques (2008, p. 160) propõe que "o corpo lúdico joga muitos jogos e brinca muitos brinquedos somente quando conhece (saber/saborear) os elementos da linguagem corporal." A autora Nhary (2013, p.4) também cita em seu estudo o termo corpo lúdico, mas através da obra do autor Huizinga:

RODRIGUES, Joice Soares; LESSA, Helena Thofehrn. Jogo, brincadeira, presença: corpos lúdicos e expressivos em aulas de dança na escola. Revista da FUNDARTE. Montenegro, p.01-18, ano 20, no 41, Abril/Junho de 2020.

Disponível em: http://.seer.fundarte.rs.gov.br/index.php/RevistadaFundarte/index> 30 de junho de 2020. 


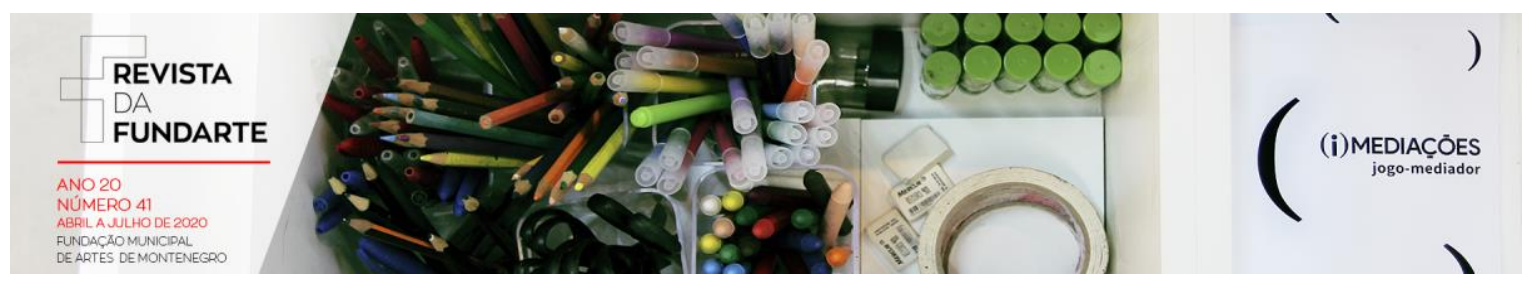

O corpo lúdico, referendado pelo entendimento de Johan Huizinga (2004) de Homo ludens, é o corpo que se diverte; é o corpo que brinca, joga, se entrega a um arrebatamento embebido em prazer e divertimento. É sobre esse corpo que falamos; um corpo que revela uma vida simbólica rica em prazer, em diversão, que vive um simulacro numa via paralela ao mundo real (HUIZINGA, 2004), mas sem dele se descolar totalmente.

O corpo lúdico é, portanto, um corpo livre que se entrega ao momento e vive o imaginário dos jogos e brincadeiras sem se desvencilhar do mundo real. E quando é que o jogo e a brincadeira viram dança? Para responder essa pergunta, é necessário trazer outra noção de corpo proposta por Marques (2008): o corpo cênico.

Nos jogos dos corpos em cena nos cenários da arte o corpo, que é lúdico, torna-se também corpo cênico: corpo que, além de dominar e usar a linguagem corporal, trabalha a própria linguagem. No corpo cênico a linguagem é construída, desconstruída, reconstruída, criada e recriada. $\mathrm{O}$ corpo cênico é criador, criativo e construtor da linguagem corporal .(MARQUES, 2008, p.161).

O corpo cênico, além de ser também lúdico, tem a possibilidade de ampliar e não somente de compreender, reproduzir, executar e interpretar: ele aprende a transformar. O lúdico na Dança pode ser utilizado em forma de jogos e brincadeiras que permitem estimular a criatividade e a imaginação, ampliando o leque de possibilidades corporais durante a aula. Ainda de acordo com Marques (2008, p.162):

[...] dançar e atuar em forma de jogo - e não em forma de reprodução ou repetição - permite que corpos lúdicos tornem-se também corpos expressivos, compartilháveis, comunicáveis e significativos para quem joga, dança e atua. Dançar articulando as múltiplas possibilidades, intersecções e relações dos elementos da linguagem corporal faz com que corpos lúdicos tornem-se corpos cênicos que dialogam, interferem, escolhem e podem transformar os cenários das artes e, consequentemente, os cenários sociais.

RODRIGUES, Joice Soares; LESSA, Helena Thofehrn. Jogo, brincadeira, presença: corpos lúdicos e expressivos em aulas de dança na escola. Revista da FUNDARTE. Montenegro, p.01-18, ano 20, no 41, Abril/Junho de 2020.

Disponível em: http://.seer.fundarte.rs.gov.br/index.php/RevistadaFundarte/index> 30 de junho de 2020. 


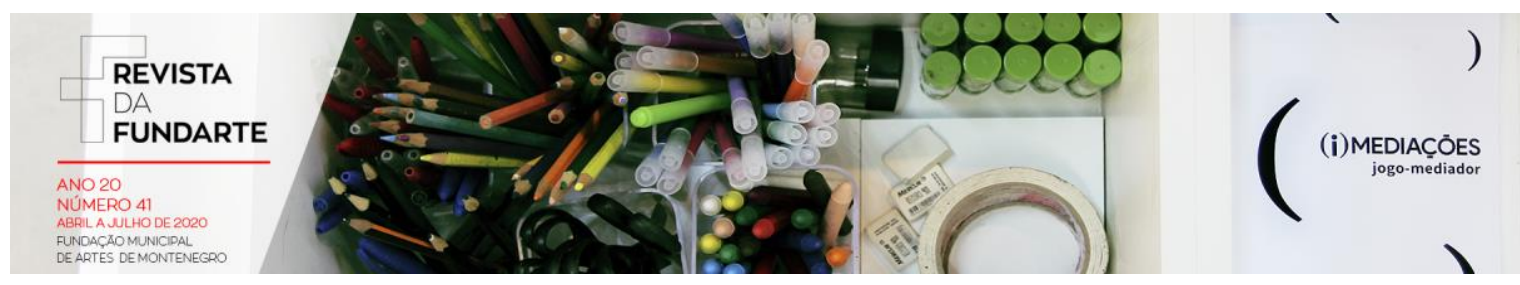

Ao trabalhar com jogos e brincadeiras na aula de Dança, estimula-se que corpos lúdicos sejam também corpos cênicos, em que "o indivíduo, se utilizando de suas habilidades e estilos como formas de linguagem, faz emergir sua noção de mundo" (NHARY, 2013, p.5). É com o pensamento nesse corpo lúdico e expressivo, que faz-se o convite para apreciar o olhar de duas professoras de Dança e suas relações com esta temática em sala de aula.

No início do diálogo sobre ludicidade, Jaciara relatou rara utilização do lúdico em suas aulas em decorrência da dificuldade de trazer essa abordagem no EJA, afirmando que quando trabalhava com adolescentes no ensino fundamental percebia maior necessidade e facilidade. Ao encontro dessa dificuldade pontuada por Jaciara, Cilena Canda traz que "[...] de modo geral, os adultos não estão habituados a participarem de vivências que envolvam o corpo, a imaginação e a criatividade." (CANDA, 2006, p. 174). Por esse motivo, a inserção de uma abordagem lúdica em aulas no EJA pode encontrar resistência por parte dos alunos.

Tauana, que atua em turmas de anos finais do ensino fundamental, refere que o lúdico auxilia no desenvolvimento motor das crianças e que com os alunos de maior faixa etária é realizado um trabalho com enfoque mais técnico de dança com coreografias. A professora destaca que através do lúdico é possível trabalhar a criatividade, a imaginação e a magia ligada ao movimento com os alunos:

[...] eles se dispõem mais a fazer do que eu chegar ali e passar uma coreografia. Não tem sentido para eles se é só a imagem do meu corpo, mas, por exemplo, se eu propor uma atividade lúdica que eu vá fazer eles deitarem no chão e trabalhar que eles imaginem que estão deitados em cima de uma nuvem, entendeu?! Que vão trabalhar a leveza, alguma coisa assim. Aí eles já ligam a imaginação deles ao movimento, acho que fica mais fácil. (TAUANA in RODRIGUES, 2018, p.31).

Nesse sentido, o uso da ludicidade pode se configurar como uma estratégia eficaz na condução de uma atividade ao invés de somente fazer uso da

RODRIGUES, Joice Soares; LESSA, Helena Thofehrn. Jogo, brincadeira, presença: corpos lúdicos e expressivos em aulas de dança na escola. Revista da FUNDARTE. Montenegro, p.01-18, ano 20, no 41, Abril/Junho de 2020.

Disponível em: http://.seer.fundarte.rs.gov.br/index.php/RevistadaFundarte/index> 30 de junho de 2020. 


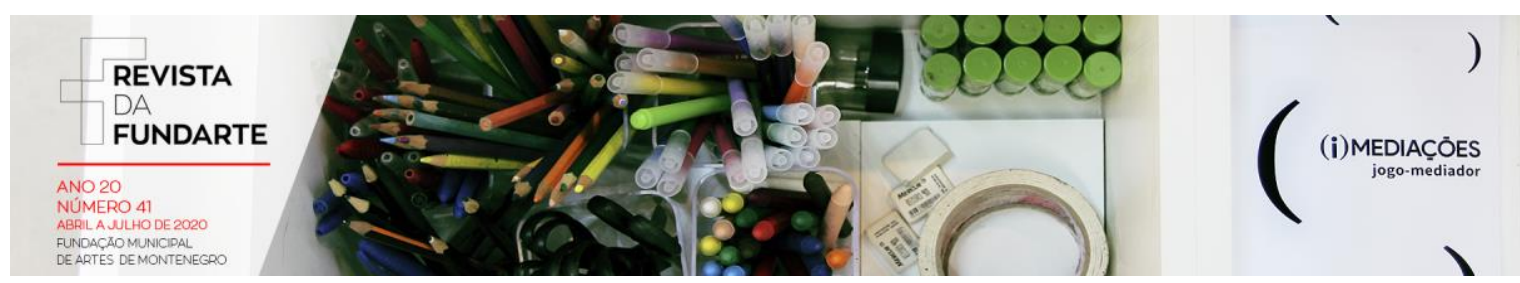

demonstração através de movimentos, tornando a imersão dos alunos mais criativa na atividade. A professora Jaciara diz que a ludicidade auxilia nas práticas de dança, podendo inserir os conteúdos de forma mais fácil e tranquila. Assim como declara Ferreira em seu estudo, "Ao aliar o brincar ao ensino de dança, acredito que pode haver um somatório relevante para a prática docente e aprendizado do aluno. Através de brincadeiras e vivências cotidianas o aluno se familiariza com o professor e o conteúdo aplicado" (FERREIRA, 2013, p. 26).

Sobre o ponto destacado acima, é preciso ter cuidado para que a atividade lúdica não vire uma ação utilitarista a ser usada em função apenas de um conteúdo específico, o que acabaria limitando o envolvimento no processo de brincar, visto que é justamente o caminho percorrido na brincadeira que dá sentido à ação do sujeito. Quando o lúdico é abordado na escola, constata-se que às vezes a sua aplicação em sala de aula se dá visando apenas o objetivo de compreensão dos conteúdos. Com isso, o lúdico acaba perdendo uma de suas principais características que é a de vivenciar de forma inteira o processo educativo que as atividades lúdicas podem proporcionar. De acordo com Canda e Souza (2010), as atividades lúdicas e o conteúdo pré-estabelecido presentes nas escolas podem ser trabalhados através de metodologias adequadas para que não se perca o momento lúdico e não se limite à compreensão somente de conteúdos programáticos.

Com relação à utilização de materiais e/ou recursos didáticos em suas aulas, as duas professoras afirmam usar variados tipos de jogos, relatando a necessidade de trazer alguns materiais, como exemplifica a professora Jaciara:

[...] quando eu fazia jogos criativos para composição, eu usava um dado gigante e algumas cartas numeradas que quando eu trabalhava com composição coreográfica, eu botava algumas coisas nas cartas numeradas, por exemplo, relacionadas ao espaço, às ações, às características de alguns movimentos, fragmentação do movimento, movimento lateral, cinesfera ampla, média, pequena, nível alto, médio e baixo, sabe, essas coisas. Aí a gente fazia esse jogo para poder fazer um exercício de composição. (JACIARA in RODRIGUES, 2018, p.31).

RODRIGUES, Joice Soares; LESSA, Helena Thofehrn. Jogo, brincadeira, presença: corpos lúdicos e expressivos em aulas de dança na escola. Revista da FUNDARTE. Montenegro, p.01-18, ano 20, oㅡ 41, Abril/Junho de 2020.

Disponível em: http://.seer.fundarte.rs.gov.br/index.php/RevistadaFundarte/index> 30 de junho de 2020. 


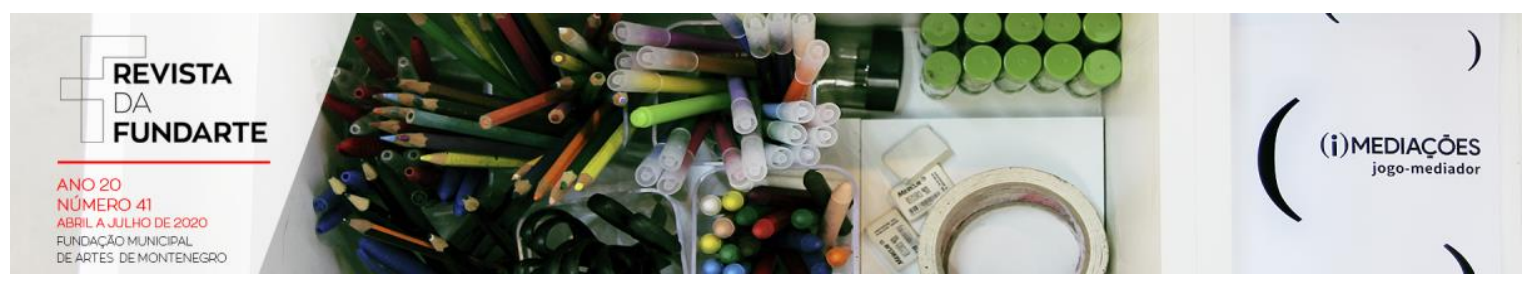

A utilização de jogos e materiais didáticos nas aulas de Dança pode se desdobrar em diferentes atividades e isso vai depender da disposição e criatividade de cada professora. Ao fazer uso desses recursos pode-se estimular os alunos a participarem das atividades e também auxiliar na interação entre eles, assim como incentivar a sensibilidade da professora, como aponta Bemvenuti:

\begin{abstract}
Observe e descubra quais jogos e atitudes lúdicas estão presentes na bagagem cultural do aluno. Experimente agregar saberes do grupo nas atividades. Incluir e ser incluído. A mágica do grupo é sensibilizada ao elegermos um jeito de brincar ou um jogo de uma criança para ser experimentado por outras crianças. $O$ aluno se reconhece como sujeito no grupo, na escola, na cidade. [...] mas vá além do banal, já conhecido, de perguntar aos pais o que eles jogavam quando criança. Faça isso também, mas vá mais além, investigue com a curiosidade de um pesquisador, de um explorador. (BEMVENUTI, 2008, p. 197 - 198).
\end{abstract}

Para além de se preocupar com o material e recursos que podemos utilizar em aula, é possível (e necessário) também valorizar as vivências de cada aluno, trabalhando a inclusão e a potencialização de singularidades, o que pode, segundo as professoras, acarretar em melhor relação entre alunos e professora. Jaciara percebe uma interação diferente com os alunos quando trabalha de forma lúdica, notando maior aproximação e uma relação mais natural entre ela e a turma. Tauana salienta seu interesse e sua disposição em sala de aula com os alunos. Desse modo, a boa relação em sala de aula e o desenvolvimento do trabalho de modo mais tranquilo com os alunos vai depender de como cada professora se dirige à turma e para se trabalhar com ludicidade na escola esse é um ponto crucial.

A vivência destas atividades precisa se dar de forma prazerosa, precisam ser propostas de modo que as crianças se envolvam ao realizá-las, e que não sejam somente um recurso didático para a aprendizagem de um conteúdo específico, o que pode se tornar um exercício cansativo, sem sentido [...] Mesmo uma aula expositiva pode se tornar lúdica se educador e

RODRIGUES, Joice Soares; LESSA, Helena Thofehrn. Jogo, brincadeira, presença: corpos lúdicos e expressivos em aulas de dança na escola. Revista da FUNDARTE. Montenegro, p.01-18, ano 20, oㅡ 41, Abril/Junho de 2020.

Disponível em: http://.seer.fundarte.rs.gov.br/index.php/RevistadaFundarte/index> 30 de junho de 2020. 


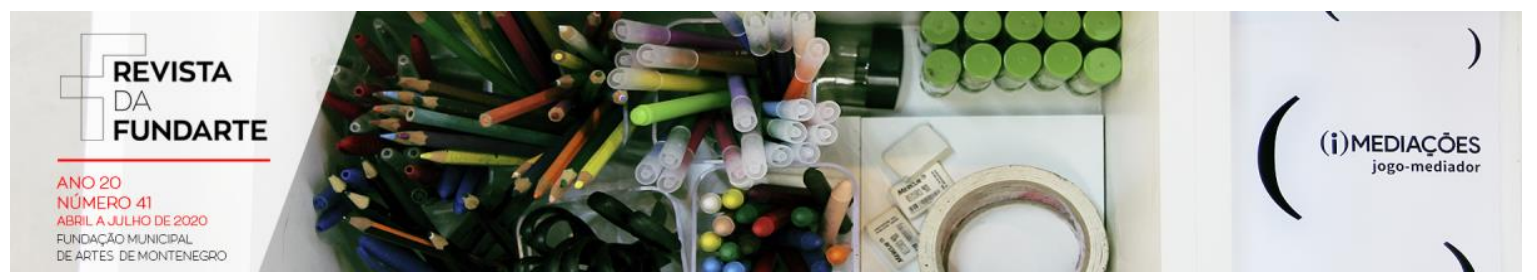

educandos se encontrarem entregues e envolvidos com o momento, se estiverem prazerosamente integrados. (PEREIRA, 2015, p.700 - 701).

A autora Pereira (2015) propõe que a professora precisa envolver os alunos em suas propostas de uma forma agradável, fazendo com que educadora e educandos estejam entrelaçados durante as atividades e o lúdico é um ótimo recurso a ser usado para que isso aconteça de uma forma mais fácil. Outro ponto importante para professoras que pretendem utilizar o lúdico para conduzir suas aulas é a participação nas atividades junto com os alunos. Esse aspecto foi questionado às professoras, buscando saber se costumavam participar das atividades com os alunos ou apenas conduziam. As duas professoras afirmaram que costumam participar, mas que às vezes também apenas conduziam as atividades para conseguirem ter um olhar externo e uma percepção diferente do que estava acontecendo na aula.

Por meio dos depoimentos das professoras, entendemos que é importante acolher essas duas posturas, as quais podem aparecer de forma única, alternada ou até mesmo simultânea durante as atividades propostas em sala de aula, já que a ação de observar pode integrar o próprio jogo. A autora Bemvenuti comenta sobre a importância da escolha pela participação na atividade junto com os alunos:

Outro modo de estimular a participação do grupo de alunos é o professor brincar junto, ser um integrante na hora de jogar, passando pelas mesmas dificuldades e alegrias, angústias e torcidas a cada desafio de resolver, competir, solucionar, demonstrar destreza, perder, integrar, compartilhar, enfim, viver junto todos os papéis possíveis no jogo com o grupo. Algumas vezes ocorre de o professor ocupar-se com outras tarefas, deixando de integrar, participar efetivamente do grupo juntamente com os alunos. 0 afastamento do professor impede também que ele possa realizar a observação sobre a forma de participação do grupo as dificuldades, as novas aquisições e conquistas, além do convívio entre os participantes. Este é um momento precioso para o exercício do observador com relação a questões inquietas. (BEMVENUTI, 2008, p.199).

RODRIGUES, Joice Soares; LESSA, Helena Thofehrn. Jogo, brincadeira, presença: corpos lúdicos e expressivos em aulas de dança na escola. Revista da FUNDARTE. Montenegro, p.01-18, ano 20, no 41, Abril/Junho de 2020.

Disponível em: http://.seer.fundarte.rs.gov.br/index.php/RevistadaFundarte/index> 30 de junho de 2020. 


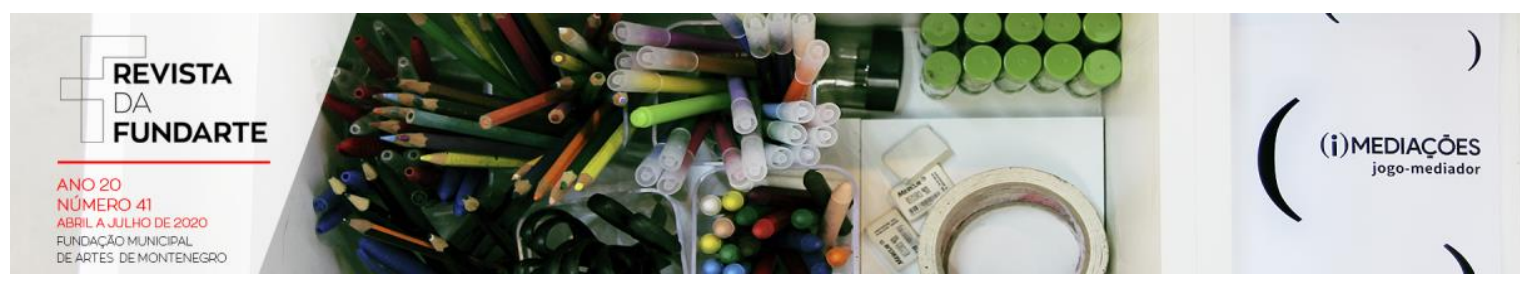

$\mathrm{Na}$ visão de Bemvenuti (2008), quando a professora se afasta do momento de participação, acaba perdendo de ver as dificuldades dos alunos mais de perto e também de experienciar a atividade e viver sensações semelhantes das que seus alunos, mas, com base na conversa com as professoras entrevistadas, entendemos que às vezes é justamente a percepção diferenciada, realizada de forma externa, que permite entender as dificuldades dos alunos.

Saber mediar e balancear essas duas posturas durante o decorrer da aula, brincar e observar de longe o que está acontecendo durante a atividade, pode servir para se ter uma aula mais fecunda em relação ao processo de aprendizagem dos alunos. Além disso, conforme pontuado por Ramos (2000), não apenas a professora intervém na atividade lúdica, mas todos os sujeitos que participam da atividade, cabendo também aos alunos adotarem uma postura coletiva e autônoma durante 0 processo de brincar.

Em relação à participação dos alunos nas atividades lúdicas, percebemos que a disponibilidade para o lúdico está bastante relacionada à faixa etária. A professora Tauana encontra maior facilidade pelo fato de ter mais turmas compostas por crianças e adolescentes, em que o trabalho da imaginação ligada à movimentação é um aspecto que, de forma geral, faz parte do cotidiano dos alunos. Já os alunos do EJA da professora Jaciara são, na sua maioria, adolescentes e adultos que trabalham, sustentam a casa e tem filhos, chegando muitas vezes cansados e abatidos na aula em decorrência do dia cansativo que tiveram. Nesse sentido, Canda (2006) aponta que o lúdico pode servir como motivador e estimulador para os alunos do EJA.

A abordagem do lúdico com as crianças é mais fácil de ser introduzida nas aulas. Segundo Almeida, "a criança é concebida como um ser diferente do adulto; não melhor ou pior. Ela possui outro campo de percepção; vê aquilo que a vista opaca do cotidiano dessa gente crescida não enxerga mais" (ALMEIDA, 2018, p. 19). No entanto, isso não quer dizer que o lúdico deve ser explorado apenas na

RODRIGUES, Joice Soares; LESSA, Helena Thofehrn. Jogo, brincadeira, presença: corpos lúdicos e expressivos em aulas de dança na escola. Revista da FUNDARTE. Montenegro, p.01-18, ano 20, no 41, Abril/Junho de 2020.

Disponível em: http://.seer.fundarte.rs.gov.br/index.php/RevistadaFundarte/index> 30 de junho de 2020. 


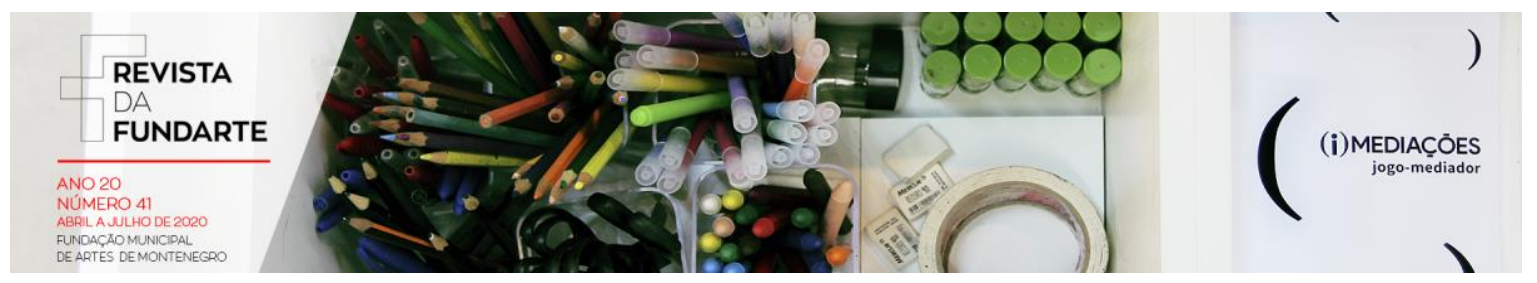

educação infantil e nos anos iniciais do ensino fundamental. Em seus depoimentos, as duas professoras entrevistadas concordam que a ludicidade pode ser trabalhada em qualquer idade, apesar de observarem maior ou menor resistência por parte dos alunos. A professora Tauana sugere que:

[...] o que modifica é a questão da fala mesmo que tu vai dirigir às pessoas e às vezes o adulto tem uma certa resistência, se tu vai trabalhar algo meio lúdico às vezes tu tem que começar pelo que é concreto, pelo o que eles conhecem digamos assim, coreográfico. A maioria dos adultos é coreografia, né... em relação à dança é o que a mídia vende. Então às vezes se tu vai desenvolver um processo que tu vai ficar um tempo, é mais fácil tu começar por aí [...]. Trabalho muito a questão das ações do Laban, levantar, agachar, girar, pular, essas ações mais cotidianas e a partir disso trabalho essa parte do lúdico e acho que isso serve para os pequenos, para os idosos também serve bastante porque além de ser uma coisa divertida, é uma coisa que eles estão trabalhando 0 movimento. (TAUANA in RDRIGUES, 2018, p.35).

Outra discussão importante de ser trazida aqui diz respeito às relações e aos limites que as professoras percebem entre dança e brincadeira, já que é uma questão recorrente nos processos educacionais na área pelo fato de a ludicidade muitas vezes ser tratada como passatempo ou recreação. Esse preconceito com a ludicidade é trazido pela autora Almeida em seu texto:

A ludicidade, que se relaciona ao prazer e ao não imposto, especialmente com a influência da visão capitalista de produtividade, se coloca em oposição a trabalho, sendo considerada, então, como tempo perdido, passatempo, como não séria. Isto justifica muito da dificuldade de ser incorporada aos processos de formação humana e de construção do conhecimento. Para validá-la, os professores se sentem obrigados a lhe atribuir um caráter utilitário, a usá-las como meios para alcançar objetivos determinados. (ALMEIDA, 2015, p.701).

O pensamento de que o lúdico só pode ser trabalhado em sala de aula se tiver a obrigatoriedade de alcançar um objetivo é uma das justificativas do porquê algumas professoras apresentam dificuldade de usar esse recurso em suas

RODRIGUES, Joice Soares; LESSA, Helena Thofehrn. Jogo, brincadeira, presença: corpos lúdicos e expressivos em aulas de dança na escola. Revista da FUNDARTE. Montenegro, p.01-18, ano 20, no 41, Abril/Junho de 2020.

Disponível em: http://.seer.fundarte.rs.gov.br/index.php/RevistadaFundarte/index> 30 de junho de 2020. 


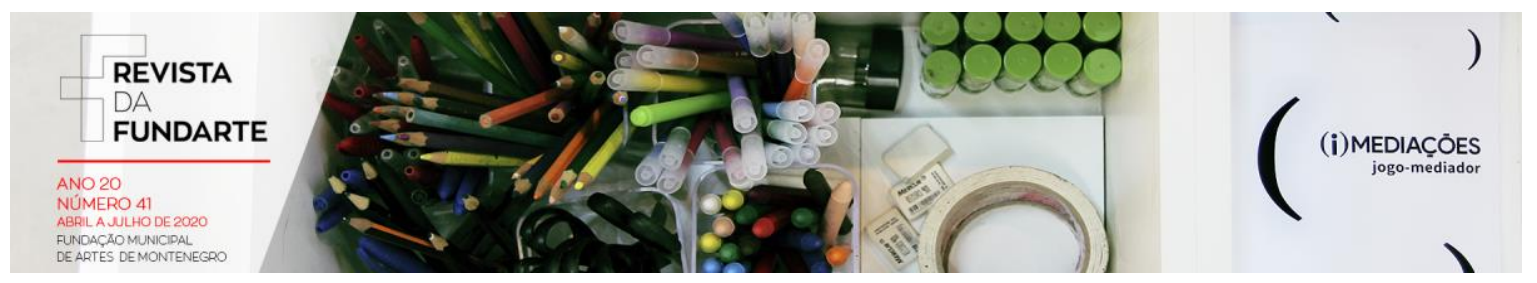

didáticas. Mas, segundo a resposta das professoras entrevistadas, a ludicidade pode ser versátil e trabalhada usando esses dois pensamentos: como recurso pedagógico, para auxiliar no alcance do objetivo da aula e na atenção dos alunos; como experiência, envolvendo o brincar e o jogar sem ter a obrigatoriedade de alcançar um resultado pré-determinado. Sobre essa questão, a professora Jaciara relata:

Então, eu sempre digo assim: "vamos começar com uma brincadeira, vamos fazer um jogo", mas esse jogo nunca é inocente (risos), sempre tem alguma coisa por trás e quando eles descobrem isso que é legal, porque os elementos que eu uso no jogo eu uso na aula depois, então é legal eles verem esse processo, sabe... "A gente tá aqui jogando, tá fazendo isso, tá fazendo aquilo e agora vamos passar para o conteúdo?". E daí o conteúdo não tem a mínima distância do que eles tinham feito no jogo. Então eles começam a entender como eu particularmente entendo o que é dança, a abordagem é lúdica, mas o conteúdo, o contexto é de dança. (JACIARA in RODRIGUES, 2018, p.36).

$\mathrm{Na}$ fala da professora Jaciara percebemos que ela faz uso do lúdico como uma introdução do conteúdo que virá depois, contendo elementos que os alunos vão usar para a aula de Dança depois, então costuma iniciar a aula com uma abordagem lúdica para em seguida partir para o trabalho de algum conteúdo específico na área. Ao encontro desse pensamento, a professora Tauana também afirma usar esse mesmo método em suas aulas, utilizando brincadeiras do contexto dos alunos e fazendo relação com os conteúdos de Dança logo depois:

[...] a gente pode usar a brincadeira como uma iniciação com certeza, principalmente a partir das coisas que eles conhecem [...] brincadeiras folclóricas, que a gente faz desde a nossa infância, para trabalhar com os alunos do terceiro ao quinto ano funciona bastante porque eles estão nessa fase da brincadeira mais de movimento, brincadeira de pular sapata, pular corda, correr. Na hora do recreio é o tempo inteiro correria, brinca de pega e a gente pode começar usando isso na aula de dança como brincadeira, depois sentar com eles depois e questionar "vocês percebem movimento nessa brincadeira? O que de movimento a gente fez nessa brincadeira? $\mathrm{O}$ que a gente faz de movimento no pular sapata? Ah, a gente usa o pular, a gente usa o girar, a gente usa o agachar". Aí eu digo "que tipo de níveis a

RODRIGUES, Joice Soares; LESSA, Helena Thofehrn. Jogo, brincadeira, presença: corpos lúdicos e expressivos em aulas de dança na escola. Revista da FUNDARTE. Montenegro, p.01-18, ano 20, oㅡ 41, Abril/Junho de 2020.

Disponível em: http://.seer.fundarte.rs.gov.br/index.php/RevistadaFundarte/index> 30 de junho de 2020. 


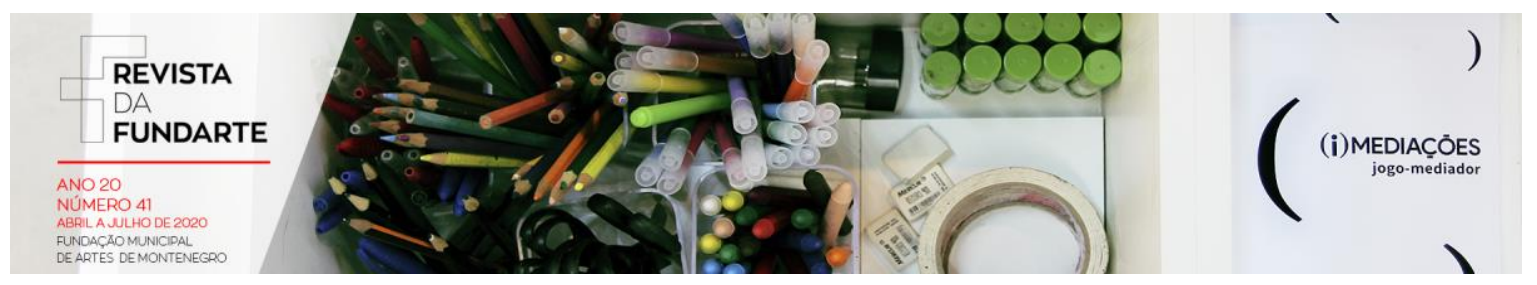

gente trabalha?" Aí tu vais questionando e eles vão te respondendo. [...] Vai questionando e depois que tu chegas numa resposta, então "bom, agora a gente vai fazer uma coreografia só com os movimentos que a gente usou na brincadeira". [...] Tu não deixas de usar uma brincadeira para chegar num objetivo técnico, mas sem deixar a diversão de lado, é o que eu acho. (TAUANA in RODRIGUES, 2018, p.37).

O método utilizado pelas duas professoras é mais voltado para o questionamento, instigando os alunos a pensarem sobre as brincadeiras que fizeram e relacionando esse processo do brincar e jogar com os conteúdos de Dança, fazendo com que a aprendizagem dos alunos possa ser prazerosa e divertida. Além disso, o lúdico parece ser usado pelas professoras como uma forma de acessar um estado corporal disponível em que os alunos se entregam ao jogo pelo fato de se interessarem pela proposta, sendo uma maneira de incentivar a realização de movimentos a serem transformados em células coreográficas posteriormente.

\section{Considerações finais}

O uso do lúdico nas aulas de Dança tem suas dificuldades, facilidades e versatilidades. Na presente pesquisa, as dificuldades se relacionaram principalmente com as diferenças entre as faixas etárias, em que as crianças aceitam as atividades lúdicas com mais facilidade enquanto os adultos do EJA parecem resistir mais; as facilidades dizem respeito à ampliação da relação professora-alunos, ao entendimento por parte dos alunos, ao prazer e à entrega que decorrem da atividade; as versatilidades porque a atividade lúdica pode mesclar a presença ou ausência de material didático e pode se moldar às necessidades dos indivíduos brincantes.

A reflexão mais importante acerca da atividade lúdica é a presença na experiência proposta. É jogo, é brincadeira, é presença. A aprendizagem pode acontecer de forma prazerosa, criativa e mágica, sem necessariamente conduzir a resultados organizados antecipadamente. $E$ isso não significa que não há

RODRIGUES, Joice Soares; LESSA, Helena Thofehrn. Jogo, brincadeira, presença: corpos lúdicos e expressivos em aulas de dança na escola. Revista da FUNDARTE. Montenegro, p.01-18, ano 20, no 41, Abril/Junho de 2020.

Disponível em: http://.seer.fundarte.rs.gov.br/index.php/RevistadaFundarte/index> 30 de junho de 2020. 


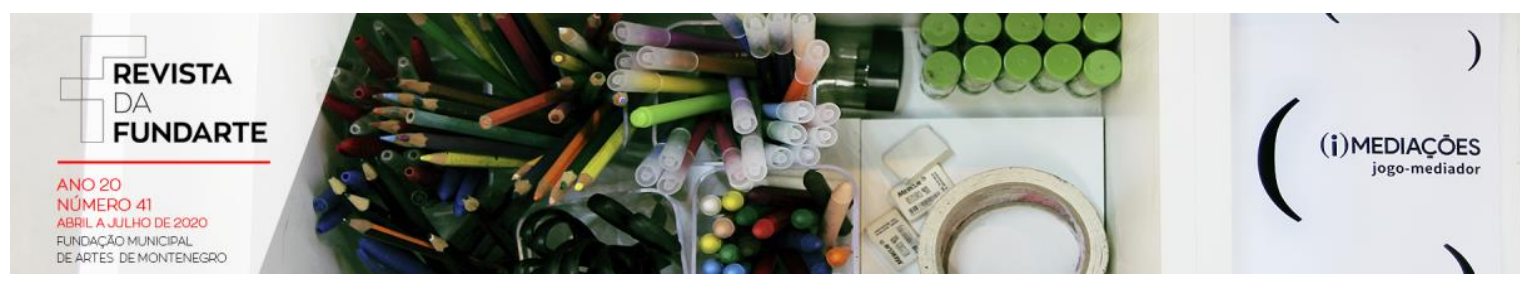

planejamento, empenho e dedicação por parte da professora, mas que essa pode deixar um espaço também para a imprevisibilidade. São justamente as surpresas no caminho que caracterizam a atividade lúdica.

Ser professora é um desafio que te convida a lidar com imprevistos e dificuldades. Ao utilizar a ludicidade nas aulas, "[...] ressaltamos a importância de o professor experimentar em seu corpo, arriscar, sentir a sensação e a alegria de cutucar e ser cutucado, abrindo espaço para a imaginação e o espanto" (ALMEIDA, 2018, p.17-18). Como a construção de um jogo de quebra-cabeças, ser professora é como ir juntando cada pecinha de experiência que temos e formando uma imagem, mas esse jogo nunca poderá se completar, pois sempre estaremos em processo de aprendizagem. Cada nova descoberta e vivência é uma pecinha nova... é um jogo infinito.

\section{Referências:}

ALMEIDA, Fernanda de Souza. Dança e Educação: 30 experiências lúdicas com crianças. São Paulo: Summus, 2018.

BENVENUTI, Alice. Espaços, tempos, ações e ambiente - Lugares da aprendizagem. IN: ULBRA (org). O lúdico na prática pedagógica. Brasília: Editora IBPEX, 2008.

CANDA, Cilene Nascimento. Aprender e brincar é só começar...: a ludicidade na alfabetização de jovens e adultos. 2006. 287 f. Dissertação de Pós-Graduação (Mestrado em Educação) - Faculdade de Educação, Universidade Federal da Bahia, Salvador, 2006. Acesso em 14 out. 2019. Disponível em: https://repositorio.ufba.br/ri/handle/ri/10172

CANDA, Cilene Nascimento; SOUZA, Regiane Santana. Educar com ludicidade: saberes e competências para a formação docente. Revista Tempos e Espaços em Educação, v. 5, p.139 - 151. Jul./dez. 2010. Acesso em 14 out. 2019. Disponível em: https://seer.ufs.br/index.php/revtee/article/view/2233

FERREIRA, Ingrid Araújo da Silva. Vamos brincar de dançar? A narrativa do processo de brincar no ensino da dança no Programa de Iniciação à Docência

RODRIGUES, Joice Soares; LESSA, Helena Thofehrn. Jogo, brincadeira, presença: corpos lúdicos e expressivos em aulas de dança na escola. Revista da FUNDARTE. Montenegro, p.01-18, ano 20, no 41, Abril/Junho de 2020.

Disponível em: http://.seer.fundarte.rs.gov.br/index.php/RevistadaFundarte/index> 30 de junho de 2020. 


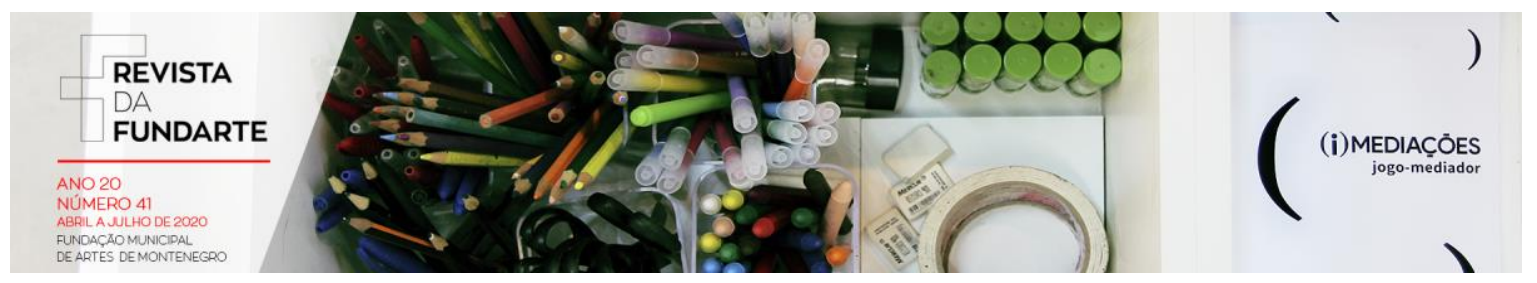

PIBID/UFRGS no ensino fundamental. 2013. 61p. Trabalho de Conclusão de Curso (Licenciatura em Dança) - Escola de Educação Física, Universidade Federal do Rio Grande do Sul, Porto Alegre, 2013. Acesso em 14 out. 2019. Disponível em: https://lume.ufrgs.br/handle/10183/87646

HUIZINGA, Johan. Homo Ludens. São Paulo: Perspectiva, 2000.

MARQUES, Isabel. Corpos lúdicos: corpos que brincam e jogam. IN: ULBRA (org). O lúdico na prática pedagógica. Brasília: Editora IBPEX, 2008.

NHARY, Tania Marta Costa. O Imaginário do Corpo Lúdico na Escola. In: EDUCERE: CONGRESSO NACIONAL DE EDUCAÇÃO, 6, 2013, Curitiba, 2013. p. 26350 - 26364. Acesso em 14 out. 2019. Disponível em: https://educere.bruc.com.br/arquivo/pdf2013/8826 5937.pdf

PEREIRA, Lucia Helena Pena. Corporeidade e ludicidade nas séries iniciais do ensino fundamental: crenças, dúvidas e possibilidades. Revista educação, Santa Maria, v. 40, n. 3, p. 697-710, set./dez. 2015. Acesso em 14 out. 2019. Disponível em: https://periodicos.ufsm.br/reveducacao/article/view/9225

RAMOS, Rosemary Lacerda. Por uma educação lúdica. IN: LUCKESI, Cipriano (org). Ludopedagogia- Ensaios 1: Educação e Ludicidade. Salvador: UFBA/ FACED, 2000.

RODRIGUES, Joice Soares. O lúdico e a dança: olhares das licenciadas em Dança que atuam em escolas da rede pública de Pelotas/RS. 2018. 72f. Trabalho de Conclusão de Curso (Licenciatura em Dança) - Centro de Artes, Universidade Federal de Pelotas, Pelotas, 2018. Acesso em 14 abr. 2020. Disponível em: https://wp.ufpel.edu.br/danca/files/2019/01/TCC-JOICE-FINAL-CD.pdf

RODRIGUES, Joice Soares; LESSA, Helena Thofehrn. Jogo, brincadeira, presença: corpos lúdicos e expressivos em aulas de dança na escola. Revista da FUNDARTE. Montenegro, p.01-18, ano 20, oㅡ 41, Abril/Junho de 2020.

Disponível em: http://.seer.fundarte.rs.gov.br/index.php/RevistadaFundarte/index> 30 de junho de 2020. 